\section{Case Reports in Dermatology}

\title{
A Case of Erythema Multiforme Major Developed after Sequential Use of Two Immune Checkpoint Inhibitors, Nivolumab and Ipilimumab, for Advanced Melanoma: Possible Implication of Synergistic and/or Complementary Immunomodulatory Effects
}

\author{
Akira Utsunomiya Noritaka Oyama Shiro Iino Natsuki Baba \\ Takenao Chino Natsuko Utsunomiya Minoru Hasegawa \\ Department of Dermatology, Division of Medical Sciences, University of Fukui, \\ Fukui, Japan
}

\section{Keywords}

Drug eruption $\cdot$ Erythema multiforme $\cdot$ Immune system $\cdot$ Ipilimumab $\cdot$ Nivolumab

\begin{abstract}
Immune checkpoint inhibitors, such as ipilimumab and nivolumab, reverse the imbalance of antitumor self-tolerance and enhance T-cell responses. Currently, ipilimumab and nivolumab have a reported therapeutic impact on unresectable or metastatic melanomas; however, they also induce immune-related adverse events (irAEs). Ipilimumab-induced cutaneous irAEs are mostly low grade and manageable, although all-grade rash may occur in approximately $45 \%$ of all patients. We here report the case of a young woman with erythema multiforme major, which developed after sequential use of these 2 immune checkpoint inhibitors for advanced melanoma of the scalp. Initially, she received 12 cycles of nivolumab monotherapy followed
\end{abstract}


by ipilimumab. A week later, multiple erythematous papulo-erythemas appeared on almost her entire body, with high-grade fever, mucosal involvements, and dyspnea. Immunohistochemistry using the lesioned skin revealed lymphocytic infiltration predominantly positive for CD8, contrasting with those for CD4 and Foxp3. Ipilimumab was stopped but she continued to receive empirical antibiotics; additionally, she was treated with intravenous steroid pulse therapy and immunoglobulin, followed by oral prednisolone. Her symptoms subsided rapidly, allowing a restart of nivolumab monotherapy alone. In our case, the long-standing preceding nivolumab monotherapy may synergistically and/or complementary have contributed to - in combination with the later administration of ipilimumab - recover antigen-responsive T-cell immunity, which is similar to the concept of immune reconstitution inflammatory syndrome, resulting in the establishment of an underlying immunopathology of erythema multiforme and life-threatening airway obstruction.

(C) 2018 The Author(s)

Published by S. Karger AG, Basel

\section{Introduction}

Immune checkpoint antibody therapy for advanced melanoma, such as with CTLA-4 inhibitor ipilimumab or PD-1 inhibitor nivolumab, reboots nonspecific and/or antigen-specific T-cell responses, causing immune-related adverse events [1]. These events mostly manifest as a low-grade rash; however, a high-grade rash (Grade 3 and 4) is noted in approximately $1.5 \%$ of all cases [2]. To date, only little information is available on the immunomodulatory action of the sequential, but not combined, approach of these 2 different agents. This report describes the first case providing implications for synergistic and/or complementary effects of a dual blockade of the PD-1 and CTLA-4 pathways, as an immunopathological setting of erythema multiforme (EM) and life-threatening airway complication.

\section{Case Report}

A 37-year-old Japanese woman presented to our hospital with a 3-year history of a black nodule, $14 \mathrm{~mm}$ in diameter, on the middle parietal scalp. The histopathology of the excised biopsy suggested malignant melanoma. She therefore underwent radical excision of the skin lesion and received local interferon injections for 12 months. Because of the development of multiple organ metastases, she received 12 cycles of nivolumab over 10 months, which was then replaced by ipilimumab, 42 days after the last nivolumab administration. One week after the first administration of ipilimumab, she became ill and had a high-grade fever with pancytopenia (white blood cells: 1,400/ $\mu \mathrm{L}$ [lymphocytes: $37 \%$ ], red blood cells: $3.52 \times$ $106 / \mu \mathrm{L}$, platelets: $1.51 \times 10^{5} / \mu \mathrm{L}$ ) (Fig. 1). She was treated with $40 \mathrm{mg} /$ day of oral prednisolone (PSL), blood transfusion, G-CSF, and broad-spectrum antibiotics, tazobactam/piperacillin (TAZ/PIPC) and trimethoprim-sulfamethoxazole (TMP/SMX), based on a high possibility for opportunistic infection. This combination therapy immediately ameliorated her pancytopenia and general status. Two days after tapering off her oral PSL to $35 \mathrm{mg} / \mathrm{day}$, however, multiple erythematous papules and nodules developed on her trunk and spread to almost her entire body, with conjunctiva injection (Fig. 2a, b).

Our patient also complained about oral soreness and dyspnea. Laboratory tests showed abnormal findings, including: white blood cells of 33,000/ $\mu \mathrm{L}$ (lymphocytes: $0.1 \%$ ), red blood cells of $5.29 \times 10^{6} / \mu \mathrm{L}$, platelets of $1.15 \times 10^{5} / \mu \mathrm{L}$, sIL2R of $6,580 \mathrm{U} / \mathrm{ml}$ (normal: $122-496$ $\mathrm{U} / \mathrm{mL}$ ), and liver dysfunction, such as alanine transaminase level of $209 \mathrm{IU} / \mathrm{L}$, aspartate 
transaminase level of 215 IU/L, and lactate dehydrogenase level of 686 IU/L (Fig. 1). Lymphocyte transformation test (LTT) was strongly positive for TAZ/PIPC and TMP/SMX, with titers of 16.2 and 12.7, respectively (normal: $>2$ ). Blood cultures and urine culture were negative.

The pathology of the lesioned skin demonstrated liquefaction degeneration and individual cell keratinization in the epidermis, with lymphocytic and eosinophilic infiltration into the superficial dermis (Fig. 3a, b). On immunohistochemistry, infiltrating T cells were predominantly positive for CD8, contrasting with those for CD4 and Foxp3 (data not shown). Based on clinicopathology, a diagnosis of EM major was made. After withdrawing ipilimumab and antibiotics, our patient was treated with intravenous methylprednisolone $(1,000 \mathrm{mg} /$ day for 3 days) and immunoglobulin ( $400 \mathrm{mg} /$ day for 5 days), followed by 50 $\mathrm{mg} /$ day of oral PSL. Her skin manifestation and systemic symptoms rapidly subsided, allowing a gradual tapering of her oral PSL and restart of nivolumab monotherapy alone.

\section{Discussion}

In our case, the long-standing preceding nivolumab therapy may synergistically and/or complementary have contributed to - in combination with the later administration of ipilimumab - the development of EM major. For example, nivolumab (impairing PD-1/PD-L1 action) enhances the expression of Fas on keratinocytes, whereas ipilimumab (impairing CTLA-4/costimulatory B7 receptors) induces Fas ligand on T cells and its soluble form, which are involved in the apoptosis of keratinocytes seen in the pathology of EM [3-5]. Moreover, Foxp3-positive Tregs constitutively express CTLA-4, efficiently enabling to coax the antigen-specific activation and transdifferentiation of naïve T cells [6]. Ipilimumab may, thus, tip the balance of nivolumab-induced immunological synapses between Tregs and antigen-presenting cells. Further feedback concern may point towards the increased T-cell activity responsible for a hypersensitivity to the particular drugs, overdriven by a combined blockade of the PD-1/CTLA-4 pathways, in our case: (i) antigen presentation of TAZ/PIPC and TMP/SMX, represented by a strongly positive LTT, and (ii) increase in drug-reactive, CD8-positive, cytotoxic T cells [7, 8]. Clinically, severe rash (Grade 3-4) has been observed to frequently appear after the combined use of ipilimumab and nivolumab (4.8\%), more than after either monotherapy (1.9 and $0.6 \%$, respectively) [9], supporting the possible involvement of synergistic and/or complementary action as an underlying immunopathology of drug-induced EM.

Another intriguing interpretation concerning the pathogenic action in our case may involve the development of immune reconstitution inflammatory syndrome (IRIS), a disease concept that occurs during the recovery of the adaptive immune system based on an imbalance of antigen-responsive CD4- and CD8-positive T cells [10-12]. IRIS can develop as a consequence of excessive inflammatory responses to previously evident or masked residual antigens [13]. The extremely high-positive LTT for antibiotics in our case may in part extrapolate the decline of antigen-driven immune tolerance, an immune reconstitution mostly seen in IRIS, thereby contributing to the pathophysiological background of EM.

\section{Statement of Ethics}

The authors have no ethical conflicts to disclose. 


\section{Disclosure Statement}

The authors have no conflicts of interest to disclose.

\section{References}

1 Michot JM, Bigenwald C, Champiat S, Collins M, Carbonnel F, Postel-Vinay S, Berdelou A, Varga A, Bahleda R, Hollebecque A, Massard C, Fuerea A, Ribrag V, Gazzah A, Armand JP, Amellal N, Angevin E, Noel N, Boutros C, Mateus C, Robert C, Soria JC, Marabelle A, Lambotte O: Immune-related adverse events with immune checkpoint blockade: a comprehensive review. Eur J Cancer 2016;54:139-148

2 Bertrand A, Kostine M, Barnetche T, Truchetet ME, Schaeverbeke T: Immune related adverse events associated with anti-CTLA-4 antibodies: systematic review and meta-analysis. BMC Med 2015;13:211.

3 Abe R, Shimizu T, Shibaki A, Nakamura H, Watanabe H, Shimizu H: Toxic epidermal necrolysis and Stevens-Johnson syndrome are induced by soluble Fas ligand. Am J Pathol 2003;162:1515-1520.

4 Okiyama N, Katz SI: Programmed cell death 1 (PD-1) regulates the effector function of CD8 T cells via PD-L1 expressed on target keratinocytes. J Autoimmun 2014;53:1-9.

5 Orbach A, Rachmilewitz J, Parnas M, Huang JH, Tykocinski ML, Dranitzki-Elhalel M: CTLA-4 • FasL induces early apoptosis of activated $\mathrm{T}$ cells by interfering with anti-apoptotic signals. J Immunol 2007;179:7287-7294.

6 Strauss L, Bergmann C, Whiteside TL: Human circulating CD4+CD25ighFoxp3+ regulatory T cells kill autologous CD8+ but not CD4+ responder cells by Fas-mediated apoptosis. J Immunol 2009;182:14691480.

7 Boutros C, Tarhini A, Routier E, Lambotte O, Ladurie FL, Carbonnel F, Izzeddine H, Marabelle A, Champiat S, Berdelou A, Lanoy E, Texier M, Libenciuc C, Eggermont AM, Soria JC, Mateus C, Robert C: Safety profiles of anti-CTLA-4 and anti-PD-1 antibodies alone and in combination. Nat Rev Clin Oncol 2016;13:473-486.

8 Guermonprez P, Valladeau J, Zitvogel L, Thery C, Amigorena S: Antigen presentation and T cell stimulation by dendritic cells. Annu Rev Immunol 2002;20:621-667.

9 Larkin J, Hodi FS, Wolchok JD: Combined nivolumab and ipilimumab or monotherapy in untreated melanoma. N Engl J Med 2015;373:1270-1271.

10 Espinosa E, Romero-Rodriguez DP, Cantoral-Diaz MT, Reyes-Teran G: Transient expansion of activated CD8(+) T cells characterizes tuberculosis-associated immune reconstitution inflammatory syndrome in patients with HIV: a case control study. J Inflamm (Lond) 2013;10:21.

11 Tappuni AR: Immune reconstitution inflammatory syndrome. Adv Dent Res 2011;23:90-96.

12 Shelburne SA 3rd, Hamill RJ, Rodriguez-Barradas MC, Greenberg SB, Atmar RL, Musher DW, Gathe JC Jr, Visnegarwala F, Trautner BW: Immune reconstitution inflammatory syndrome: emergence of a unique syndrome during highly active antiretroviral therapy. Medicine (Baltimore) 2002;81:213-227.

13 Gunthard HF, Saag MS, Benson CA, del Rio C, Eron JJ, Gallant JE, Hoy JF, Mugavero MJ, Sax PE, Thompson MA, Gandhi RT, Landovitz RJ, Smith DM, Jacobsen DM, Volberding PA: Antiretroviral drugs for treatment and prevention of HIV infection in adults: 2016 recommendations of the International Antiviral Society-USA Panel. JAMA 2016;316:191-210. 


\section{Case Reports in Dermatology}

\begin{tabular}{|c|c|}
\hline \multicolumn{2}{|c|}{ Case Rep Dermatol 2018;10:1-6 } \\
\hline DOI: $10.1159 / 000485910$ & $\begin{array}{l}\text { (C) } 2018 \text { The Author(s). Published by S. Karger AG, Basel } \\
\text { www.karger.com/cde }\end{array}$ \\
\hline
\end{tabular}

Utsunomiya et al.: EM Induced by Two Immune Checkpoint Inhibitors

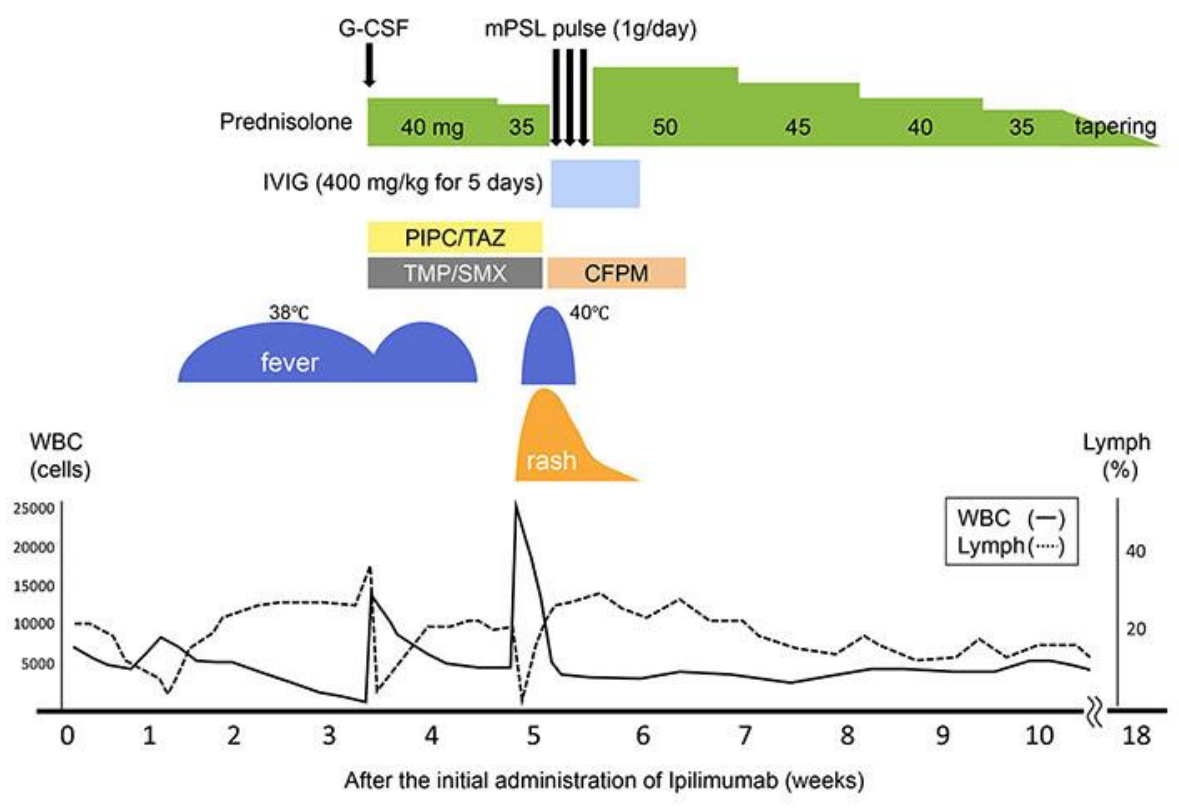

Fig. 1. Clinical course of our case.
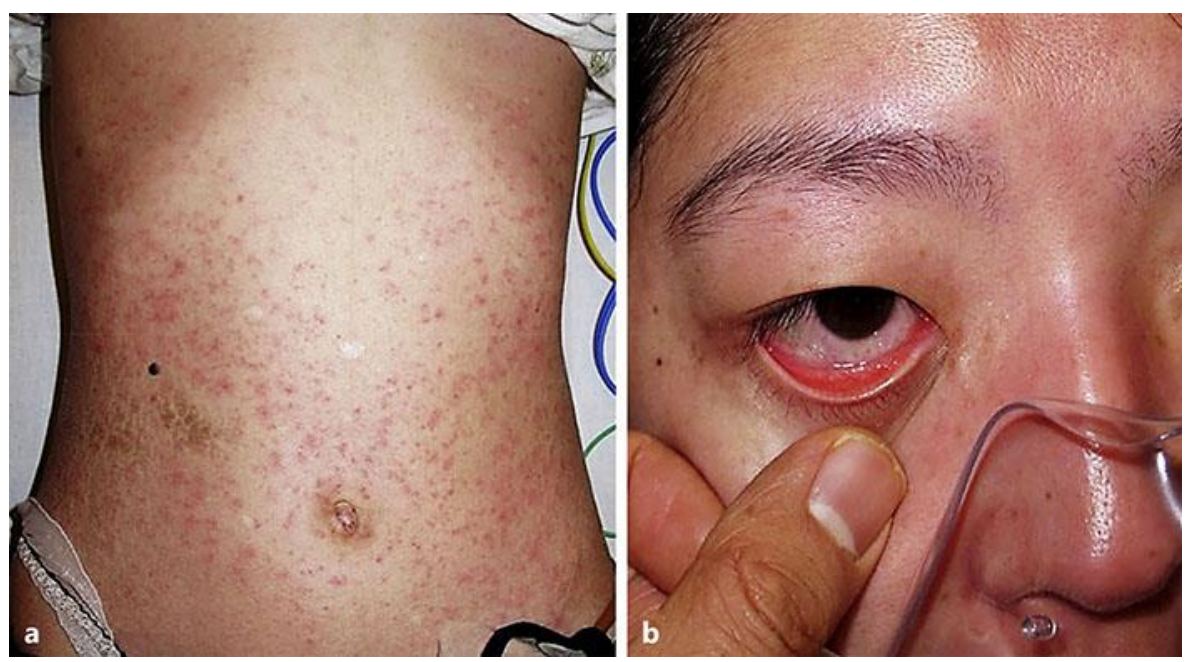

Fig. 2. Multiple erythematous papules and nodules on our patient's trunk that spread to the extremities and face (a), accompanying mucosal involvement such as conjunctival injection (b). Soreness of the oral mucosa and dyspnea were noted. 

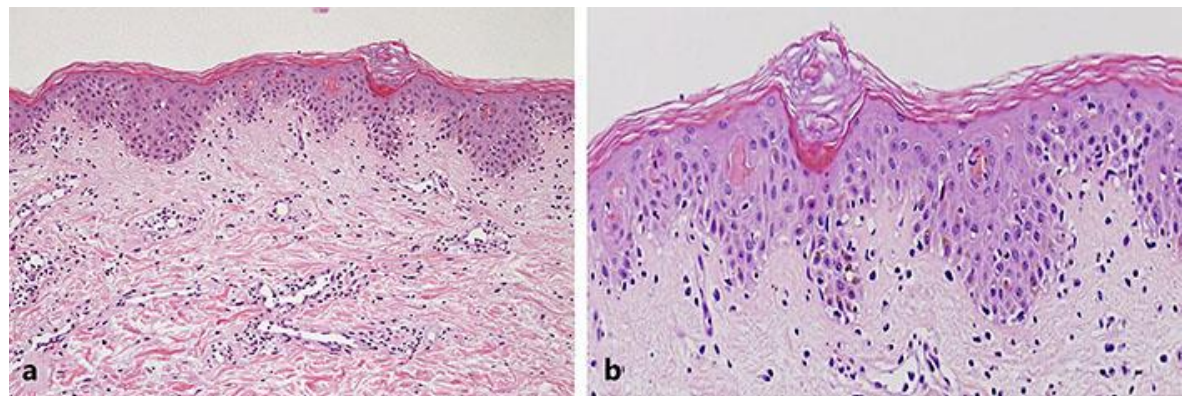

Fig. 3. Histology of the skin biopsy from her abdominal erythematous papules showing multifocal epidermal necrosis and dense perivascular infiltration of lymphocytes (HE staining; $\mathbf{a} \times 100 ; \mathbf{b} \times 400$ ). 